\title{
The knowledge level of rheumatoid arthritis patients about their disease in a developing country. A study in 168 Bangladeshi RA patients
}

\author{
A. K. M. Kamruzzaman ${ }^{1} \cdot$ Minhaj Rahim Chowdhury ${ }^{1} \cdot$ Md Nazrul Islam $^{1} \cdot$ Imtiaz Sultan $^{1} \cdot$ Shamim Ahmed $^{1} \cdot$ \\ Abu Shahin ${ }^{1}$ - Mohammad Mahbubul Alam ${ }^{1}$ - Md. Ak Azad ${ }^{1}$ - M. Masudul Hassan ${ }^{1} \cdot$ Md Zahid Amin $^{1}$. \\ Sudeshna Sinha ${ }^{1} \cdot$ Habib Imtiaz Ahmad $^{1} \cdot$ Md Nahiduzzamane Shazzad $^{1}$ • Sonia Nasreen Ahmad ${ }^{1} \cdot$ Syed Atiqul Haq $^{1}$. \\ Johannes Jacobus Rasker ${ }^{1}$
}

Received: 3 October 2019 / Revised: 29 October 2019 / Accepted: 14 November 2019 / Published online: 11 December 2019

(C) The Author(s) 2019

\begin{abstract}
Objectives To assess disease-related knowledge of rheumatoid arthritis (RA) patients

Patients and methods Consecutive RA patients were invited from the rheumatology departments of BSMM University, Dhaka, Bangladesh. The Bangla version of the Patient Knowledge Questionnaire (B-PKQ) was used. Correlations between the B-PKQ scores and clinical-demographic data were measured using Pearson's correlation coefficient. Impact of independent variables on the level of knowledge about RA was analyzed through multiple regression analysis. Possible explanatory variables included the following: age, disease duration, formal education level, and Bangla Health Assessment Questionnaire (B-HAQ) score. Analysis of variance (ANOVA) was used to test the difference between demographical, clinical, and socioeconomic variables. For statistical analysis, SPSS statistics version 20 was used.

Results A total of 168 RA patients could be included. The mean B-PKQ score was 9.84 (range 1-20) from a possible maximum of 30. The mean time for answering the questionnaire was $24.3 \mathrm{~min}$ (range 15-34). Low scores were observed in all domains but the lowest were in medications and joint protection/energy conservation. Knowledge level was higher (15.5) in 6 patients who had RA education before enrollment. B-PKQ showed positive correlation with education level $(r=0.338)$ and negative correlation with HAQ $(r=-0.169)$. The B-PKQ showed no correlation with age, disease duration, having first degree family member with RA, education from other sources (neighbor, RA patient, nurses), or information from mass media.

Conclusions Disease-related knowledge of Bangladeshi RA patients was poor in all domains. Using these findings, improved education and knowledge will result in better disease control.

Key Points

- Little is known about the knowledge of RA patients regarding their disease and its treatment in Bangladesh and in developing countries in general.

- We found that the knowledge of Bangladeshi RA patients regarding their disease was poor in all domains; it correlated positive with education level and negative with function (HAQ), but showed no correlation with age or disease duration.

- The findings of this study can be used for improving current patient education programs by health professionals and through mass media.

- Better disease control of RA may be achieved by improving patient knowledge in a developing country like Bangladesh, but also in other parts of the world.
\end{abstract}

Keywords Bangladesh $\cdot$ Developing country $\cdot$ Education $\cdot$ Patient knowledge level $\cdot$ Rheumatoid arthritis

Electronic supplementary material The online version of this article (https://doi.org/10.1007/s10067-019-04859-w) contains supplementary material, which is available to authorized users.

Johannes Jacobus Rasker

j.j.rasker@utwente.nl

1 Faculty of Behavioral, Management and Social Sciences, Department Psychology, Health and Technology, University of Twente, PO Box 217, 7500 AE Enschede, The Netherlands 


\section{Introduction}

Rheumatoid arthritis (RA) is a chronic, systemic, inflammatory disease that affects about $1 \%$ of the population [1]. It may lead to irreversible joint damage and systemic complications. In Bangladesh, the prevalence of RA in rural, urban slum, and urban affluent regions are $0.7 \%, 0.4 \%$, and $0.2 \%$ respectively [2]. The burden of RA is very high for patients their families and society; RA may lead within a decade of its onset to work disability defined as a total cessation of employment in between 51 and $59 \%$ of patients [3]. The age-adjusted mortality of those affected exceeds that of the general population [4, 5] Prognosis is uncertain and treatment is often complicated especially in a developing country, involving long-term medication and control, maintaining energy conservation, and preventing joint deformities, despite the fact that newer treatments have become available the last decennia [6].

It is important that RA patients receive education about their disease, the treatments that are available; they should learn how to handle the ever changing symptoms and the pain of RA in their daily lives [7, 8]. Especially women with their daily chores of cooking and cleaning, which are a heavy burden in a country like Bangladesh, and young patients need knowledge of RA and its treatment in order to handle their disease [9]. Several questionnaires have been developed to assess the disease-specific knowledge of RA [10-15]. .Currently, two validated patient knowledge questionnaires are available: the Hill PKQ [16] and the ACREU (Arthritis Community Research and Evaluation Unit) [15]. In the ACREU [11] questionnaire, a 5-point Likert scale is used, but this style cannot be used for a questionnaire in which factual questions are asked and knowledge is measured. [17] The patient knowledge questionnaire (PKQ) has been applied for assessing general knowledge about RA, its possible etiology, symptoms, drug treatments, physical exercises, the knowledge regarding joint protection, energy conservation $[10,17,18]$, and how to relieve pain [16]. .The PKQ was developed by Hill et al. [10] and has also been used in other studies, for assessing disease-specific knowledge of RA patients [7, 17]. The PKQ is proven to be a consistent and reliable instrument for evaluating this knowledge. It is a self-administered questionnaire with 16 multiplechoice questions about the following topics: (a) general knowledge of RA, the possible etiology, symptoms of the disease, and the meaning of laboratory tests; (b) the medications and their use; (c) exercises; (d) how to protect the joints and how to conserve energy. Each question has one, two, or three correct options and all questions give the alternative options to say "I don't know," in order to minimize the effect of a patient's wish to deny his or her lack of knowledge. The total score is 30 correct responses, out of a maximum of 80 possible responses, and the instrument is easy and quick to apply. The Bangla version of the PKQ (B-PKQ) has been adapted and validated [19]. The knowledge of RA patients in Bangladesh regarding their disease has not yet been assessed and little is known of disease-related knowledge of RA patients in developing countries in general.

The purpose of the study was to evaluate disease-specific knowledge of patients with rheumatoid arthritis in Bangladesh by using the B-PKQ.

\section{Patients and methods}

This was an observational study. Patients $\geq 18$ years, of both genders fulfilling the 2010 American College of Rheumatology (ACR) criteria for the classification of RA [20], were consecutively invited to participate from March 2013 to September 2014 , in the outpatient and inpatient departments of Rheumatology, Bangabandhu Sheikh Mujib Medical University, Bangladesh. The B-PKQ was used to assess the knowledge level of RA patients regarding their disease. A semistructured questionnaire containing the B-PKQ, B-HAQ, and clinical-demographic variables was handed to each participant and filled in directly. For the illiterate patients, a clinical assistant read the questions and wrote down the answers.

Descriptive statistics, i.e., mean and standard deviation (SD), were used where applicable. Correlations between the PKQ scores and clinical-demographic variables were measured using Pearson's correlation coefficient. ANOVA was used to test the significant difference between demographic, clinical, and socioeconomic variables. For statistical analysis, SPSS statistics version 20 was used. The results are expressed as frequencies, percentages, and ranges for categorical data, means and standard deviation for normal data.

Ethics The study was approved by the Ethics Committee of the Bangabandhu Sheikh Mujib Medical University Shahbagh, Dhaka, Bangladesh. The study was performed following the Declaration of Helsinki principles, and informed written consent was given by all participants before enrollment. The registration no. of the study was BSMMU/2013/10251.

\section{Results and observations}

A total of 168 RA patients could be included; there were no refusals. Their mean age was $39.52(\mathrm{SD} \pm 11.43)$ years, with a range of 18 to 64 years. Mean disease duration was 65.12 (SD $\pm 58.19)$ months with a range of 3 to 264 months. The disease duration was $0-5$ years in $114(67.9 \%)$ patients and more than 5 years (60 months) in $54(32.1 \%)$ cases. In this series, 138 $(82.1 \%)$ patients were female and 30 males $(17.9 \%)$. There were $36(21.5 \%)$ illiterate patients. Primary and secondary education had been attended by 118 (70.2\%) subjects, and the mean number of completed years of formal education was $6.43(\mathrm{SD} \pm 4.27)$ years. One hundred and eight (64.3\%) 
patients were housewives and other occupations are summarized in Table 1 . Ninety (53.6\%) patients were from rural areas and the remaining from urban areas. The monthly family income of 57 participants was less than 10,000.00 taka, 99 study subjects in between 10,000-20,000 taka, and the rest 12 participants more than 20,000 taka. One US\$ is 84.495 BD taka (July 2019). The demographic characteristics of the study subjects are shown in Table 1.

One hundred and fifty-one (89.9\%) patients did not have RA in first degree relatives. Twenty-four patients (14.3\%) obtained knowledge from mass media and 144 (85.7\%) from other sources (neighbor, RA patient, nurses). The majority (151,
$89.9 \%$ ) were under the care of the rheumatology outpatient department (OPD) and $11(6.5 \%)$ were treated by internists. The mean B-PKQ score of those patients who were treated by internists was 7.73 SD 3.26 and of those treated by the rheumatology department was 9.98 SD 3.99 (difference NS $p=$ 0.35). There was no structured education system for RA patients but one patient got education from her internist and 5 patients from the rheumatology OPD) (see Table 4) Hundred and sixty-two (96.4\%) patients did not get any education.

The mean B-PKQ score was 9.84 (SD \pm 4.05$)$ from a possible maximum of 30 , scores ranging from 1.00 to 20 . The mean time for answering the questionnaire was $24.3 \mathrm{~min}$ (range 15-
Table 1 Demographic characteristics of study subjects $(n=168)$

\begin{tabular}{|c|c|c|c|}
\hline Demographics & Mean \pm SD & $\mathrm{n}$ & $(\%)^{*}$ \\
\hline \multicolumn{4}{|l|}{ Age in years } \\
\hline $18-30$ & & 44 & $(26.2)$ \\
\hline $31-50$ & & 101 & $(60.1)$ \\
\hline $51-65$ & & 23 & $(13.7)$ \\
\hline Total & & 168 & $(100.0)$ \\
\hline \multicolumn{4}{|l|}{ Sex } \\
\hline Male & & 30 & $(17.9)$ \\
\hline Female & & 138 & $(82.1)$ \\
\hline Total & $39.52 \pm 11.43$ & 168 & $(100.0)$ \\
\hline \multicolumn{4}{|c|}{ Education level (completed year of formal education) } \\
\hline Illiterate ( 0 year) & & 36 & $(21.5)$ \\
\hline Primary and Higher Secondary (1-12 yrs) & & 118 & $(70.2)$ \\
\hline Bachelor and above (> 12 yrs) & & 14 & $(8.3)$ \\
\hline Total & $6.43 \pm 4.27$ & 168 & $(100.0)$ \\
\hline \multicolumn{4}{|l|}{ Occupation } \\
\hline Housewife & & 108 & $(64.3)$ \\
\hline Govt. service & & 8 & $(4.7)$ \\
\hline Private service** & & 22 & $(13.1)$ \\
\hline Businessman & & 4 & $(2.4)$ \\
\hline Farmer & & 4 & $(2.4)$ \\
\hline Rickshaw or Van puller & & 2 & $(1.2)$ \\
\hline Student & & 8 & $(4.8)$ \\
\hline Other & & 12 & $(7.1)$ \\
\hline Total & & 168 & $(100.0)$ \\
\hline \multicolumn{4}{|l|}{ Place of living } \\
\hline Rural & & 90 & $(53.6)$ \\
\hline Urban & & 78 & $(46.4)$ \\
\hline Total & & 168 & $(100.0)$ \\
\hline \multicolumn{4}{|l|}{ Per month income (taka) } \\
\hline$>20,000.00$ & & 12 & $(7.2)$ \\
\hline $10,000-20,000.00$ & & 99 & $(58.9)$ \\
\hline$<10,000.00$ & & 57 & $(33.9)$ \\
\hline Total & & 168 & $(100.0)$ \\
\hline
\end{tabular}

*Percent value in parenthesis

**Private service means: non-govt. service like bank officer, private school teacher, and company worker $S D$, standard deviation 
$34 \mathrm{~min})$. For the initial part of the questionnaire, related to the general aspects of rheumatoid arthritis (RA) including etiology, symptoms, and laboratory tests, the mean score was 3.03 (SD \pm 1.57) (maximum score $=9$ ). The second component of the questionnaire covers medications used for rheumatoid arthritis. Out of a maximum score of 7 , the mean score achieved by the patients was 2.48 ( $\mathrm{SD} \pm 1.29)$. The third component refers to exercises and the mean score was $2.51(\mathrm{SD} \pm 1.60)$ (maximum score $=7$ ). The last component covers joint protection and energy conservation, with a maximum score of 7 . The mean for the population studied was $1.96(\mathrm{SD} \pm 1.43)$. The B-PKQ total score and domain wise score are shown in Table 2 an example of the questionnaire is shown in Table 3.

\section{Response outcomes}

\section{General knowledge including etiology, symptoms, and laboratory tests}

With regard to general knowledge of RA, 49 (29\%) of patients answered that the cause of the disease was unknown and 35 $(21 \%)$ believed bacteria or virus could trigger it. Thirty-three percent patients $55(33 \%)$ believed trauma could cause the disease and 102 (61\%) did not know the answer. Ninety subjects $(54 \%)$ knew RA was a long-term disease; 15 (9\%) believed that the disease could be cured; 117 (70\%) patients believed RA only involved joints, and 26 (15.5\%) patients knew that RA occurred in old age. The patients correctly identified fatigue 107 (64\%), anemia 87 (52\%), and nodules 36 (21\%), as common symptoms of RA, and 76 (45\%) patients did not know. As regards laboratory testing, patients knew that erythrocyte sedimentation rate (ESR) (20\%) and C-reactive protein (CRP) (20\%) were associated with activity of the disease, and the majority $121(72 \%)$ did not know that laboratory testing is used to evaluate their disease.

\section{Medications and their use}

In the section regarding medications, 62 (37\%) patients were aware that non-steroidal anti-inflammatory drugs
(NSAIDs) are used to relieve pain, swelling, and stiffness. Erroneously, 30 (18\%) believed NSAIDs could stop disease progression. Although the majority 117 (70\%) answered that NSAIDs should be taken with food to reduce dyspeptic symptoms, the most commonly reported side effect was indigestion $77(46 \%)$ and anorexia $52(15 \%)$. Almost half of them $70(42 \%)$ were aware that methotrexate is a diseasemodifying drug that can cause remission of the disease. Yet, diclofenac and indomethacin were also mentioned by 5 (3\%) and $33(20 \%)$, respectively, as being diseasemodifying drugs, and $110(66 \%)$ of the patients who answered this question did not know the answer. (Appendix IV) With regard to NSAIDs, 59 (35\%) of the individuals thought they should be taken only for severe pain. See table (Appendix IV). The total will not be 168, because each patient has to give 2 or 3 answers from each question. So the answers sometimes overlap and sometimes do not overlap.

\section{Exercises}

About one third 58 (35\%) of the patients believed that exercises could reduce the chance of a joint deforming. However, 47 (28\%) answered that exercises were not necessary if they led a normally active life, and 82 (49\%) patients did not know. 109 (65\%) patients mentioned that walking was the most common exercise beneficial for RA, followed by slow running 37 (22\%), and 94 (57\%) did not know. Again, regarding exercises, the majority 92 (55\%) of patients replied that they should perform their exercises if their joints felt painful or stiff. Twenty-two percent 33 (22\%) said they would stay in bed most of the day and 11 (7\%) said they preferred not to do any exercises at all.

\section{Joint protection and energy conservation}

With regard to joint protection, 69 (41\%) patients said that when they had an inflamed wrist, they exercised the wrist several times a day to preserve flexibility. Thirty-two (15\%) said they would wear splints on their wrist. Yet, 73 (44\%) of the patients erroneously said they would use their wrist as
Table 2 The B-PKQ total scores and domain wise scores $(n=168)$

\begin{tabular}{llcr}
\hline & Min-max & Range & Mean \pm SD \\
\hline Time for data collection (minutes) & & $15.0-34.0$ & $24.33 \pm 5.71$ \\
B-PKQ score (total) & $0-30$ & $1.0-20.0$ & $9.84 \pm 4.05$ \\
B-PKQ score in general aspects & $0-9$ & $0.0-8.0$ & $3.03 \pm 1.57$ \\
B-PKQ score in medications & $0-7$ & $0.0-6.0$ & $2.48 \pm 1.29$ \\
B-PKQ score in exercises & $0-7$ & $0.0-7.0$ & $2.51 \pm 1.60$ \\
B-PKQ score in joint protection and energy conservation & $0-7$ & $0.0-5.0$ & $1.96 \pm 1.43$ \\
\hline
\end{tabular}

$n$, number of participants; $S D$, standard deviation; $B-P K Q$, Bengali version of Patient Knowledge Questionnaire 
much possible, 23 (14\%) would avoid any movement by keeping their wrist in the same position most of the time, and $77(46 \%)$ patients did not know the answer. Also here, the total will not be 168 , because each patient has to give 2 or 3 answers for each question. So, answers sometimes will overlap, sometimes not (Appendix IV).

As methods of joint protection, the option to slide objects rather than to lift them was correctly chosen by $31 \%$ and the use of larger joints rather than the smaller ones was correctly chosen by $10 \%$ of patient, while $57 \%$ did not know. Only $20 \%$ of the patients replied correctly that they would use the palm of their hands rather than their fingers to open jars, while $23 \%$ chose to have power-assisted steering on their car as a way to protect their joints. On the other hand, many patients made wrong choices regarding some other methods of joint protection, like acting as if their arthritis was non-existent (16\%), to grip objects tightly (30\%), and 54\% opted for protecting their joints by applying heat or ice to the joints. Almost half of the patients $(49 \%)$ stated that they conserved their energy if they were tired by doing only what was necessary, but $48 \%$ said they would take a short rest and then do all things they had planned. Only $39 \%$ of the individuals correctly chose for balancing periods of work and rest, and $45 \%$ chose sitting while ironing, as energy conservation strategy. However, $38 \%$ said that carrying objects with both hands would be a method of conserving energy.

\section{Age, educational level, disease duration, relatives, and mass media}

In this series, the group of patients of 18-30 years had the highest B-PKQ score $9.97( \pm 3.77)$, those of 31-50 years had $9.86 \pm 4.21$ and $51-65$ years B-PKQ scores $9.47 \pm 3.95$ (difference NS $p=0.89$ ), see Table 3 and 4.
Those who had high educational level had a higher B-PKQ score (bachelor and above B-PKQ score $13.86( \pm 3.76)$ ); illiterate patients' B-PKQ score was $8.06( \pm 4.08)$; the difference was statistically significant $(p<0.001)$.

In those with disease duration of rheumatoid arthritis, 0-5 years, the B-PKQ score was $9.55(\mathrm{SD} \pm 4.29)$ and was non-significantly different from those with disease duration $>5$ years $10.44(\mathrm{SD} \pm 3.42)(p=0.183)$.

The B-PKQ scores in those patients who had first degree relatives with RA was $11.53(\mathrm{SD} \pm 4.75)$, those without $\mathrm{RA}$ in 1 st degree relatives $9.65(\mathrm{SD} \pm 3.93)$ difference $\mathrm{NS}(P=0.07)$.

Most subjects in this study, 144, did not get any knowledge regarding RA from mass media and had low B-PKQ of $8.06 \pm$ 4.08. The B-PKQ score was $11.50(\mathrm{SD} \pm 5.03)$ in those who got knowledge from other sources, and the B-PKQ score was 9.56 ( $\mathrm{SD} \pm 3.8$ ) in those who got knowledge from mass media; the difference was significant ( $p=0.03$ ).

Age, education, duration of disease, history of rheumatoid arthritis in 1st degree relatives, knowledge gathered from different sources, and B-PKQ score status are shown in Table 4.

The Bengali-Patient Knowledge Questionnaire (B-PKQ) score showed statistically significant positive correlations with the education level $(r=0.33, p=<0.001)$ and negative correlations with B-HAQ score $(r=-0.169, p=0.0290)$. The B-PKQ showed no correlation with the age of the patients $(r=0.12, p=$ $0.88)$, or duration of the disease $(r=0.12, p=0.13)$. Correlation of B-PKQ score with age, monthly income, education level, and duration of disease and HAQ score is shown in Table 5.

\section{Discussion}

The purpose of this study was to discover how much patients with RA knew about their disease and its treatment. The

Table 3. Example of questionnaire, question 8. The majority gives the wrong answers 8.2 and 8.5

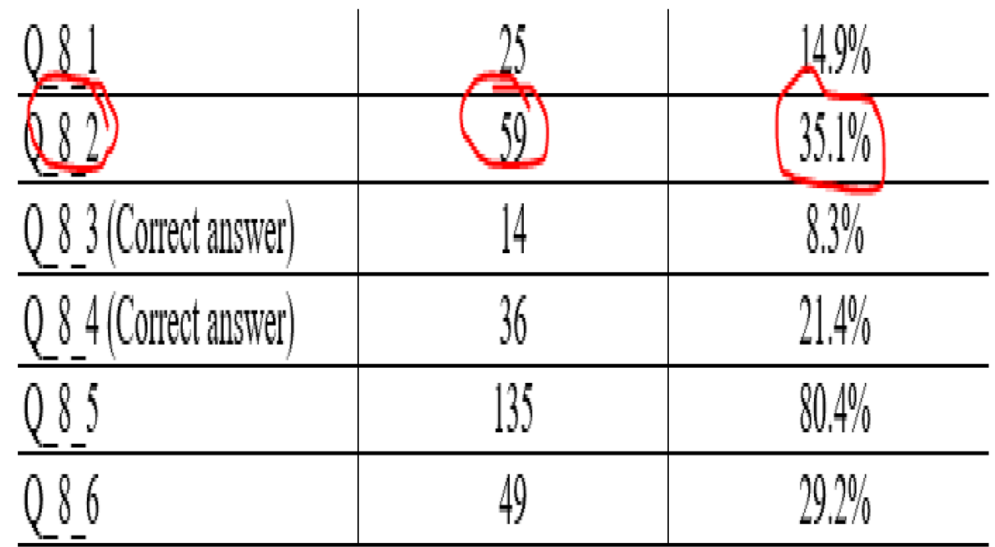

Right answers were as follows: 8 3. According to what you know, it is important to take NSAID before pain increase in any activity (14, 8.3\%); $8 \_4$. Take NSAID if pain starts to get worse $(36,21.4 \%)$.

Wrong answers were as follows: 8 _ 1 . It will not cause addiction $(25,14 \%) ; 8$ 2. Only take when severe pain $(59,35 \%) ; 8$. Take always in full stomach $(135,80.4 \%) ; 8 \_6$. Do not know $(49,29.2 \%)$ 
Table 4 Age, education, duration of disease, history of rheumatoid arthritis in 1st degree relatives, knowledge gathered from different sources and BPKQ score status $(n=168)$

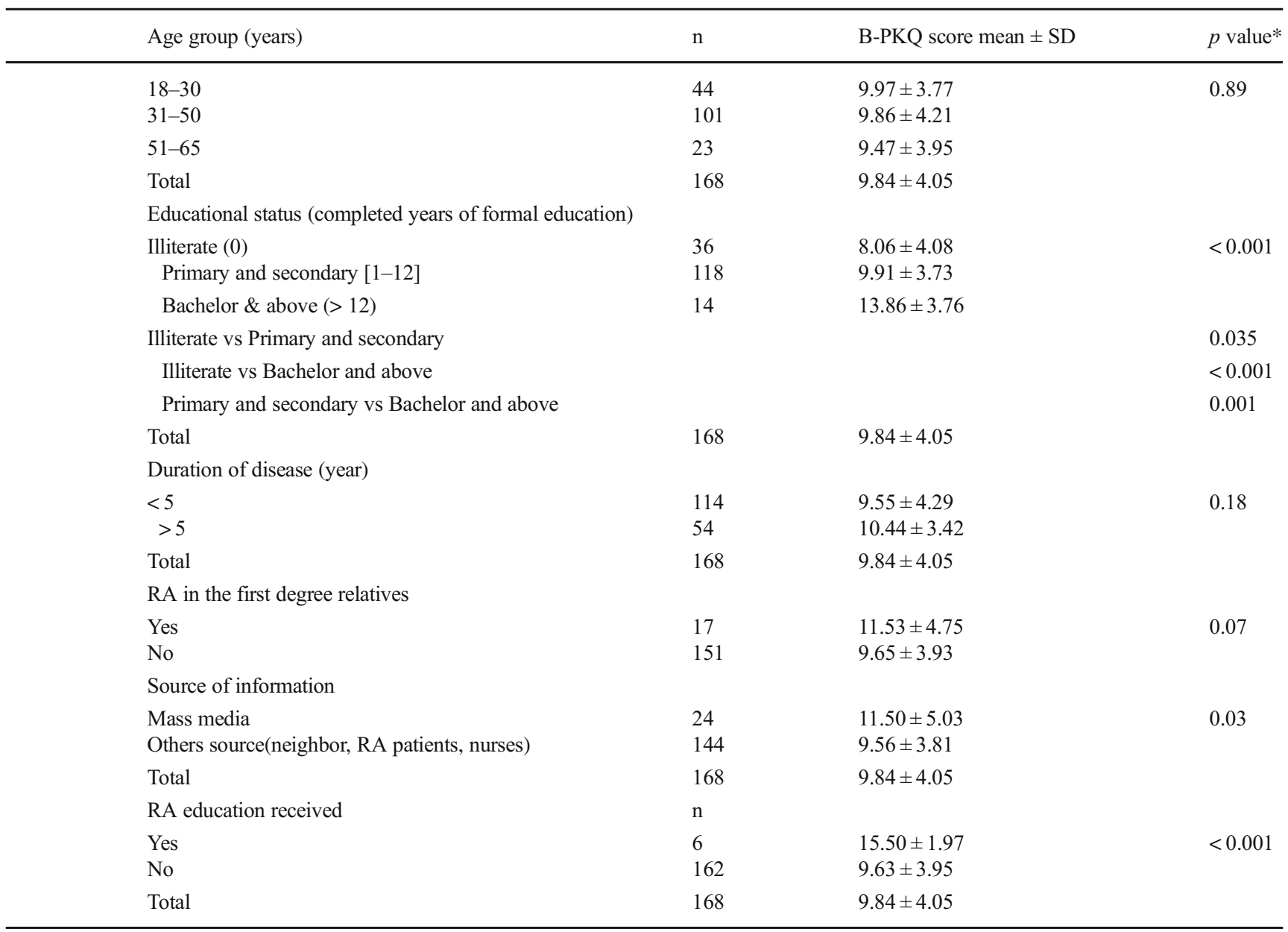

*Test done by ANOVA/ $t$ test

$B-P K Q$, Bengali-Patient Knowledge Questionnaire; $S D$, standard deviation
Bangladeshi RA patients showed a wide range of variability in the knowledge of their disease, with B-PKQ scores ranging from 1 to 20 out of a maximum score of 30 . These figures were lower than those of Hill et al. [10], who found PKQ scores ranging from 3 to 28 and also than those of Helliwell

Table 5 Correlation of B-PKQ score with age, education level, and duration of disease $(n=168)$

\begin{tabular}{lll}
\hline & $r$ value & $p$ value* \\
\hline Age & +0.01 & 0.88 \\
Education level & +0.33 & $<0.001$ \\
Income /month & +0.15 & 0.06 \\
Duration of disease & +0.12 & 0.13 \\
B-HAQ score & -0.169 & 0.029 \\
\hline
\end{tabular}

*Test done by Pearson correlation coefficient

$B-P K Q$, Bengali-Patient Knowledge Questionnaire; $B-H A Q$, Bengali Health Assessment Questionnaire et al. [17] with scores ranging from 5 to 26 . The mean B-PKQ score for the 168 evaluated Bangladeshi patients was 9.84 (SD 4.05). This score was lower than the score of 16 as reported by Hill et al. [10] who evaluated 70 RA patients. However, it must be emphasized here that in the population evaluated by that group, the mean number of complete years of formal education was 9.7 (ranging from 9 to 15 years) while in this study, the mean was 6.43 years and $21.5 \%$ of the patients were illiterate. Also in the study by Helliwell et al. [17], the mean PKQ score for knowledge in 77 RA patients was 16 . Considering the low level of education seen in the Bangladeshi RA patients, we wondered whether the knowledge obtained by them could be the result of the number of years they had been suffering from RA; however, the PKQ score did not show a statistically significant association with disease duration. Other studies [7, 10, 11, 14] also had failed to observe any correlation between disease duration and the level of knowledge. 
Although patients older than 65 years of age were excluded from our study, there was no correlation between age and disease-specific knowledge. Lineker et al. [14] observed a decreased knowledge with increasing age when applying the ACREU questionnaire to patients with RA. This group included individuals of up to 85 years of age in their sample. The study by Vignos et al. [ 11] did not include patients over 65 years of age, and in the study by Hill et al. [10], patients over 75 were excluded. Neither of these studies found a correlation between age and level of knowledge about RA.

In the Bangladeshi patients, a positive correlation was found between scores measuring knowledge and the number of completed years of formal education. Hill et al. [10] also observed this correlation despite the fact that the patients she studied had a higher level of formal education (their number of years of education was 9.7, ranging from 9 to 15). Vignos et al. [11] also observed an association between the level of education and the scores of knowledge.

The patients in our study showed less knowledge about PKQ components such as medications (mean score 2.48 out of 7), joint protection, and energy conservation (mean score 1.96 out of 7). Similar results were observed by Hill et al. [10] with a mean score of 3.3 for items regarding medications and 3.9 for joint protection and energy conservation. In a study by Judy Barlow et al [7] studied knowledge in RA patients with different disease duration; they found that the lowest PKQ scores were achieved in the sections related to medications and exercises.

With regard to medication, the most erroneous answer (80\%) was that pain killers should always be taken on a full stomach. The most frequently stated side effect (46\%) was indigestion. This was also found by Hill et al. [10], where $62 \%$ of the patients reported indigestion as the most common adverse effect.

In a study by Kay and Punchak [21], most patients stated that they especially would like to receive information/brochures about the side effects of RA medication. The poor performance of patients in Bangladesh regarding questions about joint protection and energy conservation could, to a certain extent, be ascribed to confusion regarding these two concepts. For instance, $38 \%$ of the patients said that carrying objects with both hands would represent means of conserving energy, while acting as if they did not have arthritis (16\%), grip objects tightly (30\%), and applying heat or ice to the joints (54\%) were supposed to be the ways to protect the joints. Although Hill et al. [10] have reported a higher score in this topic of the PKQ, they observed the same difficulty in distinguishing between the two concepts. Applying ice or heat as a way to protect the joint for example was also reported by a large portion of the UK patients $(43 \%)$ in the study by Hill et al. [10].

The relatively good performance of Bangladeshi patients regarding questions about exercises and RA should be mentioned. One third $(35 \%)$ believed that exercises help to prevent joint deformities, and the majority stated that one of the best ways to exercise was walking $(65 \%)$ and that, in the active stage of disease, exercises $(55 \%)$ should be made according to the individual's flexibility, rather than resting all day. These results are very similar to those obtained by Hill et al. [10]. In this regard, it is important to comment that the original PKQ was published in the 1980s and that currently, the prescription of physical activities in RA patients has changed. Thanks to the improved drug treatment, the prognosis of RA has improved and many RA patients are fit enough to be instructed how to increase muscle strength and perform aerobic exercises, even in early stages of the disease. [22-24]

In a recent study in Turkey by Bozbaş and Gürer [25] among $225 \mathrm{RA}$ patients, the PKQ was validated; the mean age of their patients was $52.8 \pm 10.8$ years and the disease duration $6.7 \pm 6.5$ years, comparable with our study. The total PKQ-RA scores were $15.1 \pm 12.6$ (ranging 0-27) which is higher than in Bangladesh. Patients' knowledge levels were related to their age, educational level, socioeconomic status, and family history of disease. A difference with our study is that most of their patients $(86.7 \%)$ reported that they had gained the information about RA from their physicians [25], while in our study, this was the case only in $3.6 \%$.

There is evidence that patient education may improve RA patients' understanding of both the progression of the disease and their knowledge of its treatments [22, 25] and of the disease-specific facts [17]. However, in the study by Kirwan et al. [26], patients who received education showed a slightly increased knowledge regarding RA and its treatment, but after 4 weeks, the effect was lost. Worldwide, many RA patients appear to have poor knowledge about their disease. Possible reasons for this have been discussed by Lorig [27]; she states that the foremost reason may be that educational programs are usually not offered inside the scope of medical practice; in other words, rheumatologists are apparently not prepared and/or do not have available time to develop and offer wellstructured educational programs. The second reason may be that not all patients are treated by a rheumatologist and many are seen by a general practitioner providing primary care. And last, but not least, Lorig mentions the lack of investment in patient education [27].

The effect of patient education needs comments. In general, the effect of patient education on patient knowledge and on their behavior is restricted and does not persist for a long time, even not with booster sessions [28]. Also, the effect of group education as advocated by Lorig is generally low and not long lasting [29]. So, especially in a developing country, new ways should be sought for improving patient knowledge regarding their own disease and its treatment.

Knowledge of rheumatic diseases in the general population is certainly influencing the knowledge of the patients, as also shown by the current study. On the other hand, it is remarkable that the general public has many wrong conceptions of the cause and treatment of rheumatoid arthritis, but also of other 
chronic diseases, as shown by a study in the Netherlands [30]. The main focus of the media regarding rheumatic diseases in the Netherlands was on patients' experiences, as well as on regular and alternative treatments [31], this will certainly be comparable in Bangladesh. We did not study the role and position of complementary medicine in the current study, but beliefs of local healers and complementary doctors in Bangladesh have certainly influenced the idea and knowledge of the RA patients regarding their disease, its causes, and its treatment.

This work was done at a tertiary level hospital in the capital city of Bangladesh, Dhaka, and so may not be representative for the whole country. It was also sometimes difficult for the patients to understand some of the questions properly.

In Bangladesh, we do not have any educational program for RA patients to enrich their knowledge regarding RA. The present study supports the need for a multidisciplinary approach for educating patients with RA; it emphasizes the necessity to help patients understand their disease process and subsequent management through proper educational programs.

\section{Conclusions}

In this study, it has been observed that in RA patients, the knowledge regarding their disease was low in all domains of $\mathrm{B}-\mathrm{PKQ}$, but especially low regarding etiology and general aspects of RA, ways of joint protection, and energy conservation. The findings of this study can be used for improving current patient education programs. The knowledge of the RA patients may then be improved by formal teaching by health professionals and education programs through mass media. Better disease control may be achieved by improving patient knowledge in a developing country like Bangladesh, but also in other parts of the world.

Acknowledgments We thank all the patients for their cooperation in the study.

\section{Compliance with ethical standards}

The study was approved by the Ethics Committee of the Bangabandhu Sheikh Mujib Medical University Shahbagh, Dhaka, Bangladesh. The study was performed following the Declaration of Helsinki principles, and informed written consent was given by all participants before enrollment. The registration no. of the study was BSMMU/2013/10251.

Disclosures

None.

Open Access This article is licensed under a Creative Commons Attribution 4.0 International License, which permits use, sharing, adaptation, distribution and reproduction in any medium or format, as long as you give appropriate credit to the original author(s) and the source, provide a link to the Creative Commons licence, and indicate if changes were made. The images or other third party material in this article are included in the article's Creative Commons licence, unless indicated otherwise in a credit line to the material. If material is not included in the article's Creative Commons licence and your intended use is not permitted by statutory regulation or exceeds the permitted use, you will need to obtain permission directly from the copyright holder. To view a copy of this licence, visit http://creativecommons.org/licenses/by/4.0/.

\section{References}

1. Abdel-Nasser AM, Rasker JJ, Valkenburg HA (1997) Epidemiological and clinical aspects relating to the variability of rheumatoid arthritis. Semin Arthritis Rheum 27:123-140

2. Haq SA, Darmawan J, Islam Md N, Uddin MZ, Bhushan B, Rhaman $F$ et al (2005) Prevalence of rheumatic disease and associated outcomes in rural and urban communities in Bangladesh: a COPCORD study. J Rheumatol 32:348-353

3. Agel J, Akesson K, Amadio PC, Anderson M, Badley E, Balint G et al (2003) The burden of musculoskeletal conditions at the start of the new millennium. World Health Organ Tech Rep Ser, Issue no (919):1-218

4. Minaur N, Jacoby R, Cosh J, Taylor G, Rasker JJ (2004) Outcome after 40 years with rheumatoid arthritis: a prospective study of function, disease activity and mortality. J Rheumatol 31(suppl 69):3-8

5. Young A, Dixey J, Cox N, Davies P, Devlin J, Emery P, Gallivan S, Gough A, James D, Prouse P, Williams P, Winfield J (2000) How does functional disability in early rheumatoid arthritis (RA) affect patients and their lives? Results of 5 years of follow-up in 732 patients from the Early RA Study (ERAS). Rheumatology (Oxford) 39:603-611

6. Lau CS, Chia F, Dans L, Harrison A, Hsieh TY, Jain R, Jung SM, Kishimoto M, Kumar A, Leong KP, Li Z, Lichauco JJ, Louthrenoo W, Luo SF, Mu R, Nash P, Ng CT, Suryana B, Wijaya LK, Yeap SS (2019) 2018 update of the APLAR recommendations for treatment of rheumatoid arthritis. Int J Rheum Dis 22:357-375

7. Barlow JH, Cullen LA, Rowe IF (1999) Comparison of knowledge and psychological well-being between patients with a short disease duration ( $\leq 1$ year) and patients with more established rheumatoid arthritis ( $\geq 10$ years duration). Patient Educ Couns 38:195-203

8. Riemsma RP, Taal E, Kirwan JR, Rasker JJ (2004) Systematic review of rheumatoid arthritis patient education. Arthritis Rheum 51:1045-1059

9. Neame R, Hammond A, Deighton C (2005) Need for information and for involvement in decision making among patients with rheumatoid arthritis: a questionnaire survey. Arthritis Rheum 53:249255

10. Hill J, Bird HA, Hopkins R, Lawton C, Wright V (1991) The development and use of a patient knowledge questionnaire in rheumatoid arthritis. Br J Rheumatol 30:45-49

11. Vignos PJ, Parker WT, Thompson HM (1976) Evaluation of a clinic education program for patients with rheumatoid arthritis. J Rheumatol 3:155-165

12. Lorish CD, Parker J, Brown S (1985) Effective patient education. Arthritis Rheum 28:1289-1297

13. Edworthy SM, Devins GM, Watson MM (1995) The arthritis knowledge questionnaire. A test for measuring patient knowledge of arthritis and its self-management. Arthritis Rheum 38:590-600

14. Lineker SC, Badley EM, Hughes EA, Bell MJ (1997) Development of an instrument to measure knowledge in individuals with rheumatoid arthritis: the ACREU rheumatoid arthritis knowledge questionnaire. J Rheumatol 24:647-653

15. Bowling A (2002) Research methods in health: investigating health and health services, 2nd edn. Open University Press, Buckingham 
16. Lindroth Y, Brattström M, Bellman I, Ekestaf G, Olofsson Y, Strömbeck B et al (1997) A problem-based education program for patients with rheumatoid arthritis: evaluation after three and twelve months. Arthritis Rheum 10:325-332

17. Helliwell PS, O'Hara M, Holdsworth J, Hesselden A, King T, Evans P (1999) A 12-month randomized controlled trial of patient education on radiographic changes and quality of life in early rheumatoid arthritis. Rheumatology (Oxford) 38:303-308

18. Hennell SL, Brownsell C, Dawson JK (2004) Development, validation and use of a patient knowledge questionnaire (PKQ) for patients with early rheumatoid arthritis. Rheumatology (Oxford) 43:467-471

19. Abeda Begum (2011) Translation, cultural adaption and validation of patient knowledge questionnaire for patients with rheumatoid arthritis from English to Bangla, BSMMU, FCPS dissertation

20. Aletaha D, Neogi T, Silman AJ, Funovits J, Felson DT, Bingham CO 3rd, Birnbaum NS, Burmester GR, Bykerk VP, Cohen MD, Combe B, Costenbader KH, Dougados M, Emery P, Ferraccioli G, Hazes JM, Hobbs K, Huizinga TW, Kavanaugh A, Kay J, Kvien TK, Laing T, Mease P, Ménard HA, Moreland LW, Naden RL, Pincus T, Smolen JS, Stanislawska-Biernat E, Symmons D, Tak PP, Upchurch KS, Vencovský J, Wolfe F, Hawker G (2010) Rheumatoid arthritis classification criteria. An American College of Rheumatology/European League Against Rheumatism collaborative initiative. Arthritis Rheum 62:2569-2581

21. Kay EA, Punchak SS (1998) Patient understanding of the causes and medical treatment of rheumatoid arthritis. Br J Rheumatol 27: 396-398

22. Niedermann K, Fransen J, Knols R, Uebelhart D (2004) Gap between short-and long-term effects of patient education in rheumatoid arthritis patients: a systematic review. Arthritis Rheum 51:388398
23. Schrieber L, Colley M (2004) Patient education. Best Pract Res Clin Rheumatol 18:465-476

24. Häkkinen A, Sokka T, Hannonen P (2004) A home-based two-year strength training period in early rheumatoid arthritis led to good long-term compliance: a five-year followup. Arthritis Rheum 51: 56-62

25. Bozbaş GT, Gürer G (2018) The knowledge level of Turkish rheumatoid arthritis patients about their diseases. Anatolian Clinic the Journal of Medical Sciences 23:12-19

26. Kirwan JR, Hewlett S, Cockshott Z, Barrett J (2005) Clinical and psychological outcomes of patient education in rheumatoid arthritis. Musculoskeletal Care 3:1-6

27. Lorig K (1995) Patient education: treatment or nice extra [editorial]. Br J Rheumatol 34:703-706

28. Riemsma RP, Kirwan JR, Taal E, Rasker JJ. (2003) Patient education for adults with rheumatoid arthritis (Cochrane review, updated 21 February 2003). Cochrane Database of Systematic Reviews;(2): CD003688, Oxford: Update Software)

29. Riemsma RP, Taal E, Rasker JJ (2003) Group education for patients with rheumatoid arthritis and their partners. Arthritis Rheum 49: $556-566$

30. van der Wardt EM, Taal E, Rasker JJ (2000) The general public's knowledge and perceptions about rheumatic diseases. Ann Rheum Dis $59: 32-3826$

31. van der Wardt EM, Taal E, Rasker JJ, Wiegman O (1999) Media coverage of chronic diseases in the Netherlands. Semin Arthritis Rheum 28:333-341

Publisher's note Springer Nature remains neutral with regard to jurisdictional claims in published maps and institutional affiliations. 